\title{
Análisis de políticas públicas en el Perú ante la crisis derivada de la Covid-19*
}

\author{
Recibido: 16 de agosto de 2020 • Aprobado: 23 de septiembre de 2020 \\ https://doi.org/10.22395/seec.v23n55a5
}

\author{
Meza Riquelme Mauricio Jorge Serafín ${ }^{* *}$ \\ Condori Pereyra, Abigail Rosse ${ }^{* * *}$ \\ Encalada Carbajal, Daniela Andrea****
}

\section{RESUMEN}

El objetivo de la investigación es analizar las medidas de políticas públicas implementadas por el gobierno peruano en la dimensión sanitaria y económica para contener la COVID-19. Para ello se basa en información secundaria, información de datos oficiales de entidades estatales que han permitido construir indicadores, utilizando Ms Excel y el SPSS. Mediante una revisión teórica de las políticas públicas, se presenta las medidas implementadas en Perú comparadas con otros países. Se demuestra las razones por las que las políticas no fueron efectivas. El trabajo concluye con propuestas para mejorar las medidas de política pública.

\section{PALABRAS CLAVE}

Políticas públicas COVID-19; sistema de salud; medidas económicas COVID-19; colapso sanitario; índice de letalidad; reactivación económica COVID-19.

\section{CLASIFICACIÓN JEL}

$\mathrm{H} 83 ; \mathrm{H} 75 ; \mathrm{C} 43, \mathrm{C} 25 ; \mathrm{H} 20$

\section{CONTENIDO}

Introducción; 1. Metodología; 2. Enfoque teórico de política para mitigar la pandemia; 3. Medidas de política sanitaria para contener la pandemia; 4. Medidas de política económica para contrarrestar la disminución de la economía; 5. Conclusiones; Bibliografía.

El presente estudio servirá para reflexionar sobre los resultados que se obtienen a nivel nacional y servirán como reflexión para adecuar un plan de reactivación económica de la región de Arequipa.

* Economista la Universidad Católica de Santa María, Arequipa, Perú. Magíster en Economía, graduado en la Universidad Nacional de San Agustín, Arequipa, Perú. Grado de doctor en Economía, graduado en la Universidad de Grenoble II, Francia, Profesor Investigador de la Facultad de Ciencias Económico-Administrativas de la Universidad Católica de Santa María, Arequipa, Perú. Dirección: Calle Samuel Velarde s/n Umacollo, Arequipa, Perú, Email: mezariquelme@ucsm.edu.pe. Orcid: https://orcid.org/0000-0003-2662-691X

*. Candidata al grado de Bachiller en Ingeniería Comercial, Arequipa, Perú. Investigadora Junior de la Unidad de Investigación de la Facultad de Ciencias Económico-Administrativas de la Universidad Católica de Santa María, Arequipa, Perú, Dirección postal: Universidad Católica de Santa María, Arequipa, Perú. Teléfono móvil: 953555517. Correo Electrónico: 74020344@ucsm.edu.pe. Orcid: https://orcid.org/0000-0002-3903-7930

*.. Candidata al grado de Bachiller en Ingeniería Comercial, Arequipa, Perú. Investigadora Junior de la Unidad de Investigación de la Facultad de Ciencias Económico-Administrativas de la Universidad Católica de Santa María, Arequipa, Perú, Dirección postal: Universidad Católica de Santa María, Arequipa, Perú. Teléfono móvil: 916778240. Correo electrónico: 74933429@ucsm.edu.pe. Orcid: https://orcid.org/0000-0003-1356-1416 


\title{
ANALYSIS OF THE COVID-19 CRISIS PUBLIC POLICIES IN PERU
}

\begin{abstract}
The goal of this research if to analyze the public policy measures implemented by the Peruvian government in the sanitary and economic dimension for the containment of the virus responsible for the COVID - 19. For that, the research is based on secondary information, data gathered from official information of State entities that have allowed the construction of indicator, using MS Excel and the SPSS. Through a theoretical review of the public policies, the study presents the measure implemented by Peru in comparison with those by other countries. The study manages to demonstrate the reasons why these policies were not effective. The work concludes with proposals for improving public policy measures.
\end{abstract}

\section{KEY WORDS}

COVID-19 public policies; health systems; COVID-19 economic measures; sanitary collapse; mortality rate; COVID-19 economic reactivation.

\section{JEL CLASSIFICATION}

$\mathrm{H} 83$; $\mathrm{H} 75$; C43, C25; H2O

\section{CONTENTS}

Introduction; 1. Methodology; 2. Theoretical approach policy for mitigating the pandemic; 3 . Measures of sanitary policy for containing the pandemic; 4 . Measures of political economy for counteracting the economic decline; 5. Conclusions; Bibliography.

\section{ANÁLISE DAS POLÍTICAS PÚBLICAS DO PERU DIANTE DA CRISE DERIVADA DA COVID-19}

\section{RESUMO}

O objetivo desta pesquisa é analisar as medidas de política pública implementadas pelo governo peruano no âmbito da saúde e da economia para conter a covid-19. Este estudo baseia-se em informações secundárias, informações de dados oficiais de entidades estaduais que permitiram a construção de indicadores, utilizando Excel e SPSS. Por meio de uma revisão teórica das políticas públicas, apresenta-se as medidas implementadas no Peru em comparação com outros países. Demostra-se as razões pelas quais essas políticas não foram eficazes. O trabalho termina com propostas para melhorar as medidas de política pública.

\section{PALAVRAS-CHAVE}

Políticas públicas covid-19; Sistema de saúde; Medidas econômicas covid-19; Colapso sanitário; Índice de letalidade; Reativação econômica pós-covid-19.

\section{CLASSIFICAÇÃO JEL}

$\mathrm{H} 83 ; \mathrm{H} 75 ; \mathrm{C} 43, \mathrm{C} 25 ; \mathrm{H} 20$

\section{CONTEÚDO}

Introdução; 1. Metodologia; 2. Abordagem política teórica para mitigar a pandemia; 3. Medidas de política sanitária para conter a pandemia; 4. Medidas de política econômica para neutralizar a queda da economia; 5. Conclusões; Bibliografia. 


\section{INTRODUCCIÓN}

El estudio analiza la efectividad de las políticas públicas COVID-19 en salud y economía del Estado peruano. Para abordar el tema, hemos inferido enfoques teóricos sobre los que se han apoyado las medidas de políticas públicas para combatir la pandemia. También ha sido necesario relacionar el caso peruano con otros países para entender su problemática, sabiendo que no es objeto del presente estudio hacer comparaciones, tampoco señalar qué país es exitoso con la implementación de las medidas sanitarias y económicas puesto que cada país tiene sus propias particularidades.

El Perú no tenía un sistema de salud acorde a las necesidades de la población; el riesgo de colapso era cuestión de tiempo. El primer caso del virus fue el 6 de marzo del 2020, ante esto el gobierno peruano implementó políticas públicas para controlar su propagación, después de esa fecha la curva de infectados no cesa de incrementarse hasta el momento de concluir la investigación.

Diversos estudios oficiales ${ }^{1}$ ayudaron a comprender la evolución de esta pandemia en el país. El acopio de información secundaria de diversa fuente permitió explicar la efectividad y las consecuencias de las medidas sanitarias y medidas económicas implementadas en Perú.

Se utilizo el estudio desarrollado por Moquillaza-Alcántara, V., Romero-Celdán, A., Munares-García, O. y Merellano-Navarro, E. (2020) y la página de Statista, lo cual ayudó a entender por qué el Perú a pesar de que adoptó medidas con mayor rapidez, no logra contener la pandemia, esto se demuestra por la elaboración de los índices de letalidad y variación de contagiados.

La investigación tiene cinco secciones que explican la metodología utilizada, le enfoque teórico de políticas sanitarias, las medidas de política sanitaria y sus consecuencias, las medidas de política económica y finalmente las conclusiones con propuestas que pueden ser útiles para mitigar los efectos que ha generado el coronavirus.

\section{METODOLOGÍA}

Basada en datos oficiales del Ministerio de Salud de Perú (Minsa) e información secundaria de fuentes reconocidas, se ha construido indicadores de la COVID-19 con un seguimiento al número de pruebas procesadas, casos confirmados, hospitalizados y fallecidos. Se ha recogido data sobre el número de camas UCI, pruebas rápidas

El Instituto Nacional de Estadística e Informática INEI, Ministerio de Salud MINSA, Encuesta Nacional de Hogares ENAHO, Ministerio de Economía y Finanzas MEF, Ministerio de Trabajo y Promoción del Empleo MTPE, ponen a disposición de los visitantes de sus sitios web un conjunto de estudios que elaboran. Material importante que ha servido para este estudio. 
y moleculares diarias, y las medidas de contención (aislamiento social, bonos económicos), como parte de las políticas públicas establecidas por el gobierno.

Para abordar el tema, se planteó el supuesto de que las medidas implementadas por el gobierno peruano no fueron efectivas para enfrentar la pandemia de la COVID-19. Se contrasta las políticas públicas con el crecimiento sostenido de la propagación del virus, medidos con indicadores estándar, también se hizo comparaciones con los índices de seguimiento de la COVID-19 de diversos países para entender el caso peruano.

Para la construcción de los indicadores ${ }^{2}$, se clasificó la información obtenida del Minsa desde el 16 de marzo, que empezó el confinamiento, hasta el 12 de agosto. Luego se elaboró una base de datos diaria en el programa Ms. Excel, donde se estimó el índice de letalidad (L) [1] y el índice de población contagiada (C) [2].

$$
\begin{gathered}
L=\frac{N^{\circ} \text { de fallecidos }}{N^{\circ} \text { Positivos }} \times 100 \\
C=\frac{N^{\circ} \text { de Positivos }}{N^{\circ} \text { de muestreados }} \times 100
\end{gathered}
$$

Se sistematizó la información, considerándose hospitalizados, personas muestreadas mediante pruebas serológicas y moleculares, índice de letalidad, índice de población contagiada, variación de contagios diarios, frecuencia de la ocupación de camas UCI, número de fallecidos.

Para estudiar el resultado de las medidas económicas, se revisó estadísticas e informes oficiales y también estudios relevantes de consultoras y organismos internacionales.

Para comprobar la efectividad de las políticas públicas se ha inferido en base a estudios revisados y medios de prensa, fortaleciendo el trabajo con acopio de 214 encuestas virtuales. La metodología se explica en el anexo 1.

\section{ENFOQUE TEÓRICO DE POLITICAS PARA MITIGAR LA PANDEMIA}

El Perú adoptó políticas sanitarias recomendadas por la Organización Mundial de Salud OMS, la cual es reconocida como autoridad rectora internacional en sanidad pública con competencias amplias y técnicas ${ }^{3}$, además, tiene la

2 La construcción de los indicadores fue útil porque se tenía información dispersa, a fines de junio las cifras fueron relativamente homogéneas con los resultados que presentamos

3 Pons Rafols (2020, p.3), en su estudio sustenta que la OMS ha perdido presencia mundial al permitir que Estados Unidos se aparte de la organización donde se argumenta la falta de liderazgo e impulso político ante la crisis sanitaria. 
responsabilidad de recomendar propuestas de mitigación y eliminación contra la propagación de enfermedades infecciosas.

De una revisión bibliográfica de estudios publicados, se infirió sobre la teoría de las políticas públicas aplicadas, para posteriormente explicar el caso peruano. Para entender el enfoque revisamos los casos de Reino Unido, Estados Unidos, Suecia y Brasil, en América Latina, países que optaron por una política a la que se denominó inmunidad de rebaño, que consistió en que el gobierno tome precauciones aislando a las personas de alto riesgo, como ancianos, dejando que se propague el virus, de tal forma que la naturaleza del humano genere sus propias defensas y logre la inmunidad colectiva. En el estudio de Espinoza Mora et al (2017), se evalúa el caso de la inmunidad del rebaño de un programa de vacunación pediátrica de estrategia de salud pública aplicado en Costa Rica, donde demuestran que la vacunación general representa una medida de gran importancia para la salud funcional, solo de esta forma se logró la inmunidad de la población en su conjunto. El estudio ha permitido conceptualizar este tipo de política pública.

China, Italia, España y posteriormente otros países de América Latina siguieron la política sanitaria recomendada por la OMS al que denominamos Enfoque del Capullo $^{4}$, que consistió en el aislamiento social obligatorio, cierre de fronteras, pruebas masivas de descarte. Países como Reino Unido y Suecia en el mes de abril reorientaron su política pública del enfoque de la inmunidad del rebaño al de Capullo, debido al crecimiento de contagio y mortalidad.

La tabla 1 resume los tipos de políticas sanitarias.

Tabla 1. Diferencias de enfoque teórico para combatir la COVID-19

\section{Enfoque de Inmunización del rebaño}

- Aislamiento total para las personas mayores de 70 años.

- Cierre de escuelas y universidades.

- Cuarentena obligatoria para casos sintomáticos.

- Cuarentena voluntaria para las familias, tanto de familiares contagiados y no contagiados.

- La cuarentena voluntaria no afecta la pérdida de empleo.

- Intensidad en el trabajo remoto.
Enfoque del Capullo ${ }^{5}$

- Aislamiento social obligatorio para toda la población.

- Cierre de fronteras de los países.

- Pruebas masivas de descarte a la población vulnerable.

- Seguimiento y tratamiento a las personas infectadas.

- Toque de queda obligatorio.

- Generación de indicadores COVID-19 para la implementación de políticas de mitigación

- Relajamiento del aislamiento según resultados

Fuente: Elaboración propia

Término utilizado por Espinoza Mora et al (2017, p.51)

5 Como podrá notarse el caso peruano refleja fielmente estas medidas de mitigación. 
Entre los riesgos para el enfoque de la inmunización de rebaño están: a) la propagación del virus puede rebasar el sistema de salud de un país; b) el nivel de mortalidad puede ser muy alto en busca de dicha inmunidad. El supuesto de la teoría de la inmunización considera el beneficio económico de que un país no va a pasar por una recesión económica severa y habrá menor pérdida de empleo, el gasto público demandará menor sacrificio, el confinamiento dará mayor flexibilidad en la movilización de las personas, porque se cuenta con la responsabilidad consciente del ciudadano. El riesgo reside en los altos índices de mortalidad que se expone a las poblaciones vulnerables.

Por su parte, en el enfoque del capullo, el riesgo es que si no cuenta con un sistema de salud fuerte, la política del aislamiento social para evitar la propagación del virus puede llegar a la saturación y al desborde del control de la pandemia; en contraste, se ha pensado que esta medida puede permitir que un Estado implemente un sistema de sanidad progresivamente cuando es precario y pueda afrontar el crecimiento de la pandemia hasta lograr el aplanamiento de la curva de infectados del virus, de esta forma se puede controlar la difusión y atender la demanda de enfermos sin saturar el sistema de salud. En este enfoque la recesión económica es fuerte, con consecuencias en la pérdida de empleo, incremento de la pobreza y mayor gasto fiscal.

La pandemia de la COVID-19 es un shock sin precedentes y viene desencadenando severos impactos sociales y económicos que implica una elevada incertidumbre sobre el futuro, en la medida que se desconoce su alcance y duración, por lo que no es conveniente aventurarse a indicar cuál enfoque es el más conveniente o qué país tuvo mayor éxito; el rebrote del virus en China, España, Francia y otros países dejan como lección que todos estamos en el ensayo de prueba y error en materia de políticas públicas sanitarias y económicas.

Las evidencias están mostrando que no existen recetas para mitigar la pandemia, por ejemplo, en el Reino Unido y Suecia retroceden en su política de inmunización de rebaño hacia el enfoque del capullo, esta decisión logró frenar la pandemia, después deciden combinar medidas de ambos enfoques ${ }^{6}$.

A su vez, Estados Unidos y Brasil continúan con la política de inmunidad de rebaño, que parece no ser la mejor opción, de ahí el hecho que los indicadores COVID-19 muestran el alto crecimiento en ambos países. Freitas, Silva y Cidade

Política pública que caracteriza al enfoque de la inmunidad. 
$(2020)^{7}$ resaltan que la política sanitaria que se lleva en Brasil socava su capacidad de control, crece la mortalidad y el país se convierte en el epicentro como foco de contagio para países vecinos. Los autores sustentan que para tomar las medidas de política sanitaria se requiere tener en cuenta la heterogeneidad de la nación en el contexto regional social. En el estudio se concluye que la población brasileña se encuentra en medio de contradicciones por las autoridades de salud pública, quienes proponen y adoptan medidas de la OMS contra las propuestas y medidas de inmunización liderada por su presidente. Luego de la lectura del estudio se desprende que la crisis en Brasil empeora por situaciones políticas.

El factor político cuenta en la lucha contra el virus. Nótese que habrá prontas elecciones presidenciales en Bolivia, República Dominicana, Perú, las legislativas en Chile, Venezuela, elecciones locales en México, Uruguay, Paraguay y Costa Rica.

Pont Vidal (2020) señala que los países llevan a cabo políticas de ensayo y error con resultados no concluyentes; por ende, se debe aprender de las medidas sanitarias llevadas a cabo por Suecia, Alemania y España. Se cree que la adaptación de estas experiencias a la idiosincrasia de cada país puede ser útil.

En este sentido, para Herrera (2020, p.3) la opción es aprender a desaprender. Las medidas sanitarias tradicionales como el enfoque de la inmunidad u otro que se están aplicando a fenómenos de epidemias contemporáneas pueden disminuir las capacidades para actuar que está llevando al crecimiento de la pandemia en todo el mundo. Repetir las medidas de la inmunidad del rebaño o del aislamiento social son modos de pensamiento tradicionales que aparentemente no logran la mitigación del virus. Por tanto, el autor recomienda que se debe aprender de la experiencia de China, que se resume en una rápida y masiva intervención del Estado, sin aceptar cuestionamientos públicos.

\section{MEDIDAS DE POLITICA SANITARIA PARA CONTENER LA PANDEMIA}

De acuerdo con los enfoques explicados por Barrios (2020), Perú optó por una mayor protección a la población, tomando las siguientes medidas:

- Aislamiento social obligatorio en todo el país.

- Cierre de fronteras y restricción del flujo de personas en aeropuertos y fronteras del país.

- Incremento progresivo de pruebas de descarte.

Los autores explican que la crisis en Brasil no solo es sanitaria, sino también política, la que se ve favorecida por las desigualdades de las clases sociales. 
- Tratamiento y seguimiento a las personas infectadas.

- Toque de queda para evitar la movilización de personas.

Con estas medidas se esperaba reducir el número de infectados gracias al confinamiento, aplanar la curva de infectados, evitar el contagio e implementar la capacidad del sistema de salud a medida que crece la pandemia.

\subsection{Evolución de la demanda y oferta sanitaria}

Las medidas implementadas fueron en un marco donde el gobierno no tenía actualizado el censo de las personas vulnerables, ni información actualizada del sector informal, las familias no estaban preparadas ni informadas para tener la disciplina del distanciamiento social, lavado de manos, adecuada ventilación de ambientes, uso de mascarillas y escudos faciales. El sistema de salud no contaba con personal médico entrenado para un sistema de rastreo de contactos adecuado, con equipamiento hospitalario, con protección sanitaria conveniente para su labor. Las familias estaban acostumbradas a realizar compras diarias y no estaban preparadas para frenar la frecuencia de sus desplazamientos para abastecerse.

De igual manera, las medidas de aislamiento no contaron con una adecuada difusión, la falta de sanciones firmes para el desacato fue parte de las debilidades.

Como consecuencia, los índices de contagio y el de letalidad se incrementan (ver Figura 1), en marzo no había pruebas para hacer un testeo masivo para identificar los casos, aislarlos y tratarlos; en abril se utilizó pruebas serológicas, sin embargo, la curva de contagio tenía una oscilación creciente entre el $3 \%$ y $4 \%$, mientras morían 100 personas diarias.

Figura 1. Índice de letalidad y población contagiadas.

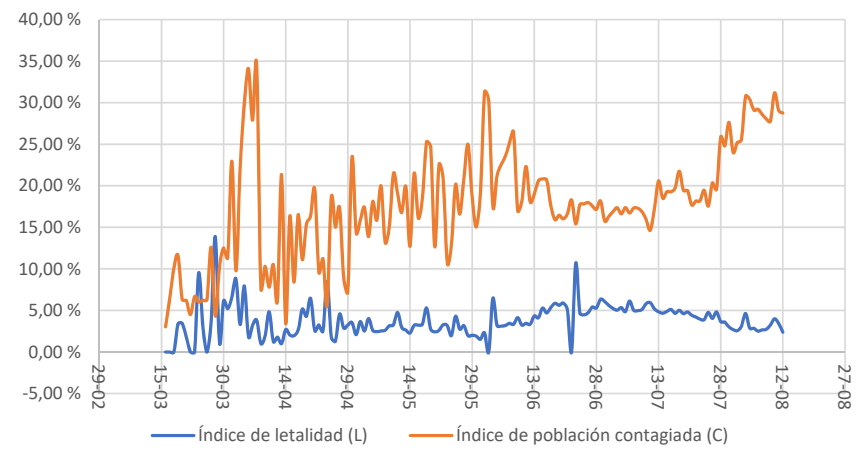

Fuente: Elaboración propia con información de MINSA 
En abril no se tomó en cuenta que las familias pobres abandonarían el confinamiento porque los ahorros se agotarían. Los modelos matemáticos mostraban que, en ausencia de aislamiento social el número de muertos crecerían exponencialmente. Herrera Romero y Reys (2020) en un estudio de campo demuestran que las medidas de confinamiento fueron brutales para las familias pobres y se convirtieron en el talón de Aquiles para no lograr controlar la pandemia.

El Estado consciente de que la población pobre era económicamente vulnerable, tenía como parte de su política otorgar subsidios monetarios de forma progresiva, el primer bono que se dispuso fue para el mes de abril, seguido de otras bonificaciones monetarias; el resultado fue que no todos lo recibieron, explicado por la falta de información para llegar a las poblaciones pobres, el subsidio se entregó por medios bancarios, sin tener en cuenta que no toda la población de este segmento estaba bancarizada.

La economía peruana se reciente más por la extensión del confinamiento, para corregir se dispone la cuarentena focalizada, algunas regiones se encuentran con un toque de queda diferenciada, algunas actividades deben empezar a funcionar de acuerdo con el plan de reactivación económica.

La figura 2 muestra la tendencia de otros países, cada uno de ellos toma decisiones para contrarrestar el avance del virus, por ejemplo, el índice de letalidad es creciente en Chile respecto a los demás países, aun cuando tienen un gasto en salud per cápita de USD 2,229, siendo el primero en el ranking de gasto per cápita en América Latina, ello no significó un gasto eficiente, porque afrontan el déficit del sistema de salud. El gasto de salud per cápita en Perú fue de USD 681 para afrontar la COVID-19, el Estado se esforzaba en implementar de manera eficiente y rápida las camas UCI, EPPs, oxigeno medicinal, ventiladores mecánicos para no colapsar el sistema de salud, pero el ritmo de la propagación crecía más rápido, así, se convertía en el pais con mayor tasa de mortalidad, ya que se tenía un indice de 84 fallecidos por cada 100.000 habitantes (la tasa más alta en relación a los demás paises). Por su parte, los países desarrollados, pese a tener un sistema de salud fuerte, afrontan serios problemas, explicado por sus propias peculariedades. 
Figura 2. Índice de letalidad por países.

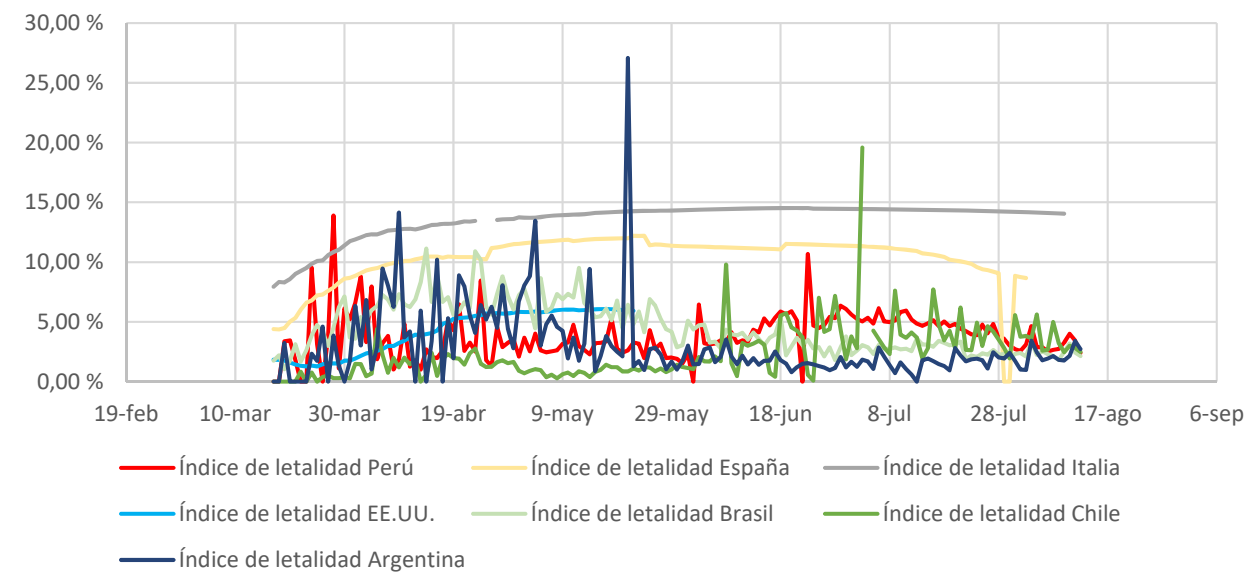

Fuente: Elaboración propia con datos del MINSA y STATISTA

El riesgo de propagación estaba medido por el índice multiplicador de contagio del virus; la figura 3 muestra un inicio del índice de 3,22, a fines de marzo alcanzaba 1,81. El Estado peruano desde abril decidió ampliar reiteradas veces la cuarentena porque la tendencia crece a 2,39, la tendencia oscilaba de 1,52 a 1,4. El gobierno buscaba llegar a 1 porque se creía que en ese momento la curva estaría plana, la cuarentena se amplió hasta el 30 de junio, fecha en que nuevamente empezó a subir el índice multiplicador de contagio. La esperanza de arribar a la meseta de la curva se hizo incierta.

Figura 3. Indicadores de aplanamiento de la pandemia en el Perú.

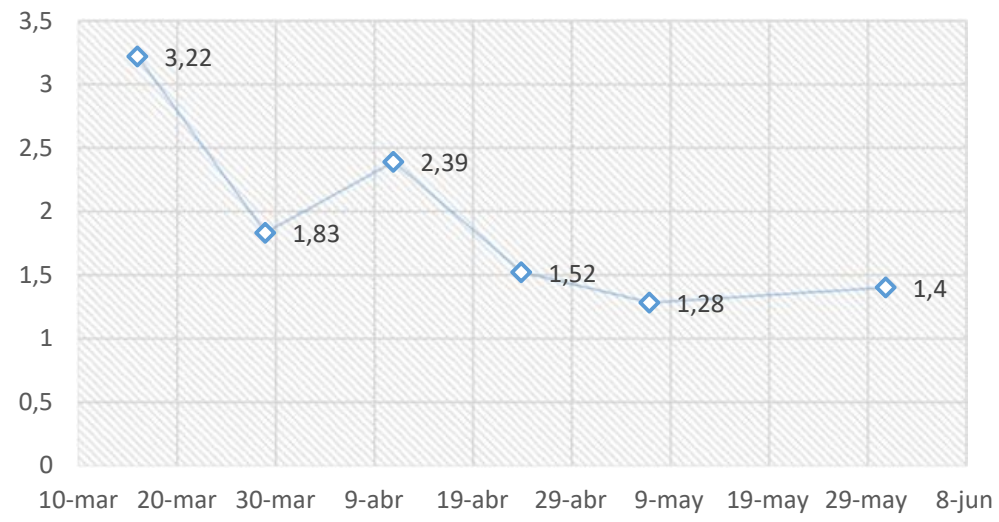

Fuente: MINSA, MEF 
Después de junio continuaron en confinamiento cinco regiones del país. La capital de Perú no entró en cuarentena porque el 60 \% de la actividad económica del país se concentra en Lima, la economía no podía seguir paralizada. El 12 de agosto se dispuso una cuarentena focalizada en 34 provincias de doce regiones en las que se incluyeron algunas provincias de Lima.

La figura 4 ilustra el sistema de salud frágil: la disponibilidad de camas UCI el 16 de marzo fue de 276 camas a nivel nacional, al 21 de mayo se habilitaron 988, al 12 de agosto se incrementó a 1606. El gobierno continuó en el trabajo de habilitar más infraestructura (hospitales COVID-19, más camas de hospitalización y UCI). En ocho regiones del Perú el sistema de salud colapsó a junio. La Defensoría del Pueblo (2020a) al 15 de agosto anunció que las entidades prestadoras de salud como los hospitales del Seguro Social, de las Fuerzas Armadas y Policía Nacional no contaban con camas UCI ni ventiladores mecánicos.

Figura 4. Evolución de las camas UCl ocupadas

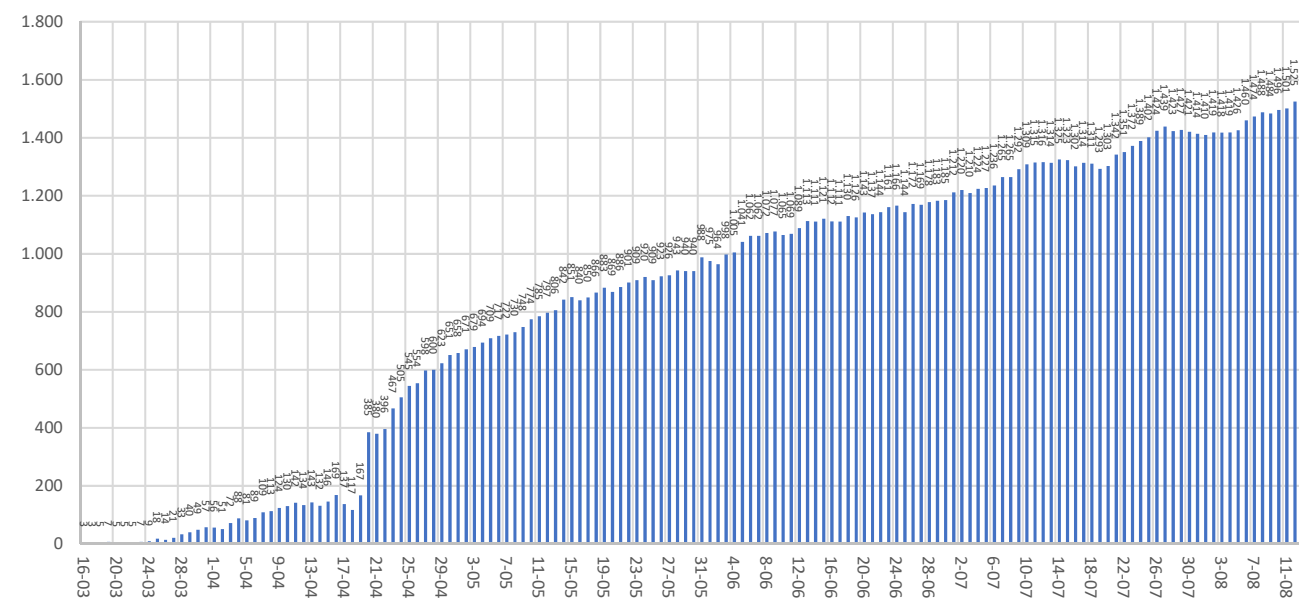

Fuente: Elaboración propia con información de la sala situacional de la COVID-19 Perú MINSA

En agosto, según información de Johns Hopkins University (2020), el Perú en comparación con el resto de los países se ubicaba en el sexto lugar como víctima de la COVID-19. La figura 5 muestra cómo fue la tendencia de los médicos contagiados en Perú. Según Galán-Rodas, Tarazona-Fernández, y Palacios-Celi (2020), al 20 de marzo había diez médicos contagiados, al 13 de agosto se incrementó a 3,398 
médicos contagiados, lo que evidenció la carencia de suministros apropiados de equipos de protección personal EPP8

\section{Figura 5. tendencia de médicos contagiados COVID-19}

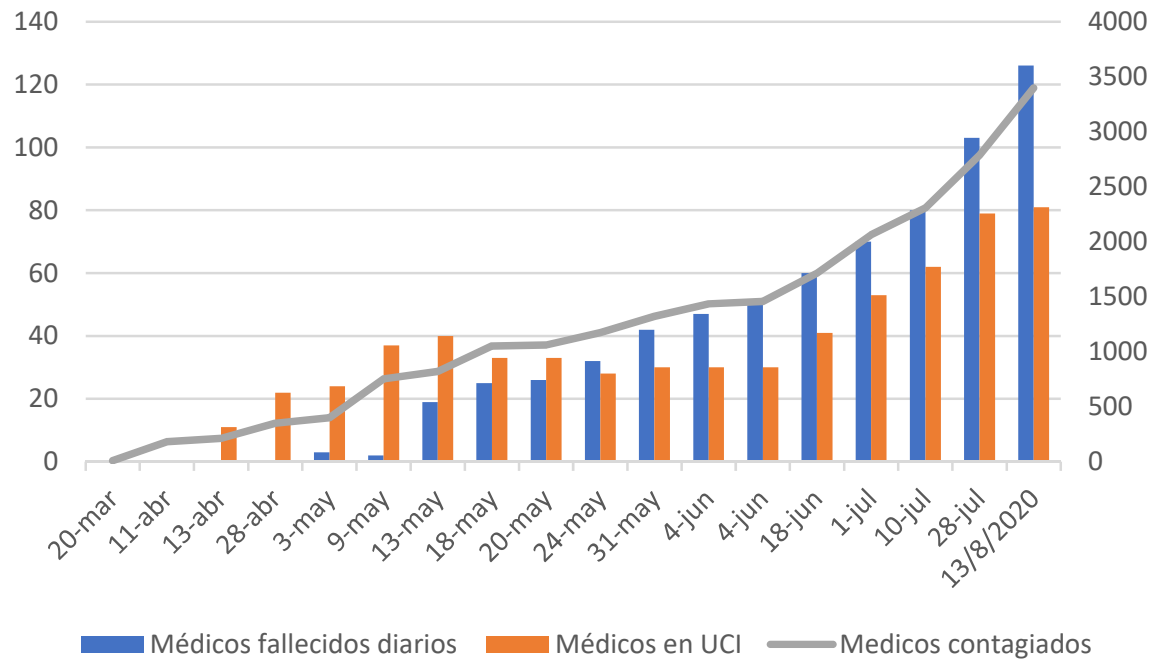

Fuente: Elaboración propia con información del Colegio Médico del Perú.

El Perú no estuvo solo en esta situación, Brasil, Ecuador, Italia y España enfrentaron la falta de EPP, exponiendo el riesgo de contagio al personal médico. Así todos los países muestran debilidades con las que afrontan la pandemia.

\subsection{Debilidades de las políticas públicas sanitarias}

Una medida de la política sanitaria fue la contención social, la cual se basó en el aislamiento social obligatorio, esta no funcionó porque fallaron en focalizar a las personas vulnerables ${ }^{9}$. La Población Económicamente Activa (PEA) llegaba a 17'462.751, donde el total de la población ocupada (PO) era 16’776.483, cuyo 72,4 \% se compone la actividad informa ${ }^{10}$. Perú no tiene un censo actualizado de la población

8 Equipos de Protección Personal (EPP).

9 Según el INEI, una primera aproximación a la pobreza se asocia con la incapacidad de las personas para satisfacer sus necesidades básicas de alimentación. Luego, se considera un concepto más amplio que incluye la salud, las condiciones de vivienda, educación, empleo, ingresos, gastos, y aspectos más extensos como la identidad, los derechos humanos, la participación popular, entre otros. Según sus datos al 2019, los pobres en el Perú llegan al 22 \% y también está compuesto por los trabajadores informales que no tienen protección social, perciben bajos ingresos.

10 Datos obtenidos del portal del INEI en los estudios de la Población económicamente activa ocupada - Tasa de empleo informal, según ámbito geográfico. 
vulnerable, sus municipalidades cuentan con uno del año 2012. Cuando el gobierno asignó el primer bono ${ }^{11}$ de $107 \$$ US no llegó a todos. Algunas autoridades municipales fueron denunciadas por asignar el subsidio a personas que no les correspondía. La población marginada al agotar sus recursos salió a las calles a buscar sustento, el gobierno clausuró mercados y otros lugares donde había contagio por aglomeración; el comercio ambulatorio creció sin que las autoridades policiales pudieran ejercer control, además que muchos policías fueron contaminados y aislados.

El gobierno destinó nuevos bonos subsidiarios canalizados a través de los bancos, sin considerar que las personas que pertenecían al sector informal o familias de zonas rurales carecían de cuentas bancarias ${ }^{12}$. Con la data de familias de la oficina de Encuesta Nacional de Hogares (Enaho) del Perú se abrieron cuentas bancarias para los beneficiarios, esto provocó largas colas en las puertas de los bancos, al no respetar el distanciamiento social se formaron focos de contagio.

Una debilidad fue el cierre de las escuelas por el confinamiento y la insuficiente intervención del Estado. Ello ha perjudicado e incrementado la desigualdad educativa; la falta de medios digitales en posición de los escolares es un problema no resuelto.

Para fortalecer la comprobación de nuestro supuesto, se realizó una encuesta abierta donde respondieron 214 personas, participaron 16 funcionarios del Estado, 91 profesionales con trabajo remoto, 5 amas de casa, 44 desempleados por la circunstancia del Covid19, 47 pequeños y microempresarios, y 11 estudiantes universitarios. Las respuestas se presentan en la tabla 2, estas se mostraron coincidentes con lo explicado precedentemente.

Tabla 2. Percepción de la efectividad de las políticas sanitarias.

\begin{tabular}{ccccc}
\hline Preguntas & Sí & A medias & No & Ignoro \\
\hline La población está informada sobre higiene, distancia- & 87 & 111 & 12 & 87 \\
\cline { 2 - 5 } miento social basado en protocolos biosanitarios & $40,65 \%$ & $51,87 \%$ & $5,61 \%$ & $40,65 \%$ \\
\hline \multirow{2}{*}{ ¿Era necesaria la cuarentena, sino habrá más muertos? } & 157 & 39 & 16 & 2 \\
\cline { 2 - 5 } & $73,36 \%$ & $18,22 \%$ & $7,48 \%$ & $0,93 \%$ \\
\hline Llegó el subsidio económico a las familias que & 18 & 95 & 92 & 9 \\
\cline { 2 - 5 } & $8,41 \%$ & $44,39 \%$ & $42,99 \%$ & $4,21 \%$ \\
\hline necesitaban & 15 & 115 & 69 & 15 \\
\cline { 2 - 5 } $\begin{array}{c}\text { ¿El Estado tiene implementado el sistema y } \\
\text { seguimiento de contagiados? }\end{array}$ & $7,01 \%$ & $53,74 \%$ & $32,24 \%$ & $7,01 \%$ \\
\hline
\end{tabular}

11 Bonificación denominada "quédate en casa".

12 MacroConsul (2020) señala la baja bancarización, base de hogares desfasada, alta informalidad como retos para la efectividad de las medidas del Estado peruano 
Meza Riquelme Mauricio Jorge Serafín; Condori Pereyra, Abigail Rosse y Encalada Carbajal, Daniela Andrea

\begin{tabular}{ccccc}
\hline Preguntas & Sí & A medias & No & Ignoro \\
\hline \multirow{2}{*}{ ¿El Estado ha logrado focalizar los focos de contagio? } & 23 & 105 & 78 & 7 \\
\cline { 2 - 5 } & $10,75 \%$ & $49,07 \%$ & $36,45 \%$ & $3,27 \%$ \\
\hline \multirow{2}{*}{ ¿En el sector informal se ignora sobre protocolos } & 91 & 89 & 27 & 7 \\
\cline { 2 - 5 } sanitarios? & $42,52 \%$ & $41,59 \%$ & $12,62 \%$ & $3,27 \%$ \\
\hline ¿La informalidad en el transporte urbano e & 164 & 32 & 11 & 7 \\
\cline { 2 - 5 } interprovincial contribuyó al contagio de la COVID-19? & $76,64 \%$ & $14,95 \%$ & $5,14 \%$ & $3,27 \%$ \\
\hline
\end{tabular}

Fuente: encuesta propia

El 52 \% de la población considera que las medidas de distanciamiento social se informaron a medias, lo que quiere decir que la inseguridad en el comportamiento de las personas ha sido un riesgo. El 73,3\% consideraron que la cuarentena ha sido necesaria, en caso contrario el sistema de salud hubiera colapsado a los días de iniciada la cuarentena. Si bien es cierto que se saturó el sistema de salud en julio, el Estado ha continuado implementándola.

El $43 \%$ de los encuestados consideran que el subsidio económico no ha llegado a las personas vulnerables, lo que ha contribuido a que el aislamiento no haya sido efectivo.

La mitigación de la pandemia reside en el hecho de aislar a las personas contagiadas, el $54 \%$ cree que ha sido a medias y el $32 \%$ no ha sido efectiva. Coincidiendo además que el Estado no ha logrado identificar los focos de contagio, lo que explicaría el crecimiento constante.

La actividad informal al ignorar los protocolos de sanidad se constituye en un foco de contagio, al respecto el 43 \% lo percibe, a ello se sumó el transporte informal que ha seguido operando en plena pandemia ante la incapacidad del Estado por controlarla.

\section{MEDIDAS DE POLÍTICA ECONÓMICA PARA CONTRARRESTAR LA DISMINUCIÓN DE LA ECONOMÍA}

\subsection{Fundamentos económicos de soporte}

Según Diaz et al. (2020), sustenta que los países andinos antes de la pandemia confrontaban dos niveles de fragilidad en materia de políticas públicas. Se identifica a Colombia y a Perú como países de menor vulnerabilidad, por contar con condiciones macroeconómicas fuertes, pero con condiciones sanitarias y domésticas débiles, mientras que, Bolivia, Ecuador y Venezuela es un grupo con altos índices 
de vulnerabilidad sanitaria y doméstica y menor condición macroeconómica que Colombia y Perú.

La tabla 3 compara lo fortaleza económica conque algunos países latinoamericanos contaban para afrontar la pandemia. Por ejemplo, la deuda pública en relación con el PBI de cada país, el Perú tenía un mejor indicador, Chile seguía con mayor financiamiento seguido de Colombia, Brasil y Argentina.

Las Reservas Internacionales Netas (RIN) con relación al PBI de cada país, Perú lideraba con la sostenibilidad de sus reservas. En cuanto al tipo de cambio en el acumulado de enero a mayo del 2020, el Perú mostraba mayor fundamento macroeconómico, la apreciación del dólar en referencia a las monedas de cada país fueron para el Perú del 3,6\%, seguido de Colombia y Chile con un deterioro de sus monedas de 10,4\% y 13,50 \% respectivamente, mientras que Brasil y Argentina presentaban una depreciación muy alta. Según Thompson Reuter (2020) citado por Semana Económica (2020, p.16) solo en el mes de abril la depreciación de la moneda peruana y de los otros países latinoamericanas eran de 1,8\% para el Perú, $11,7 \%$ para el peso chileno, 16,2 \% para el peso colombiano, 24,5\% para el peso mexicano y para el real brasileño llegaba a $27,1 \%$. La depreciación de las monedas se explica por la salida de divisas dada la desconfianza de los capitales extranjeros en permanecer en los países latinoamericanos.

Tabla 3. Indicadores macroeconómicos de países latinoamericanos.

\begin{tabular}{cccccc}
\hline $\begin{array}{c}\text { Deuda pública/PBI } \\
\text { Diciembre 2019 }\end{array}$ & \multicolumn{2}{c}{ RIN Diciembre 2019 } & \multicolumn{2}{c}{$\begin{array}{c}\text { Tipo de cambio acumulado } \\
\text { enero-mayo 2020 }\end{array}$} \\
\hline Perú & $27 \%$ & Perú & $30 \%$ & Perú & $3.60 \%$ \\
Chile & $29 \%$ & Brasil & $12 \%$ & Colombia & $10.40 \%$ \\
Colombia & $54 \%$ & Colombia & $14 \%$ & Chile & $13.50 \%$ \\
Brasil & $88 \%$ & Chile & $13 \%$ & Brasil & $34.80 \%$ \\
Argentina & $99 \%$ & Argentina & $12 \%$ & Argentina & $53.40 \%$ \\
\hline
\end{tabular}

Fuente: Elaboración propia con información de FMI, Bloomberg, BCRP.

En el segundo trimestre del 2020, el BCRP (2020a) explicaba que los países con confinamiento estricto tuvieron un costo económico muy alto, explicado por las medidas sanitarias implementadas y por el alto grado de informalidad, como lo muestra la figura 6. 
Figura 6. PBI segundo trimestre 2020 (variación porcentual interanual)

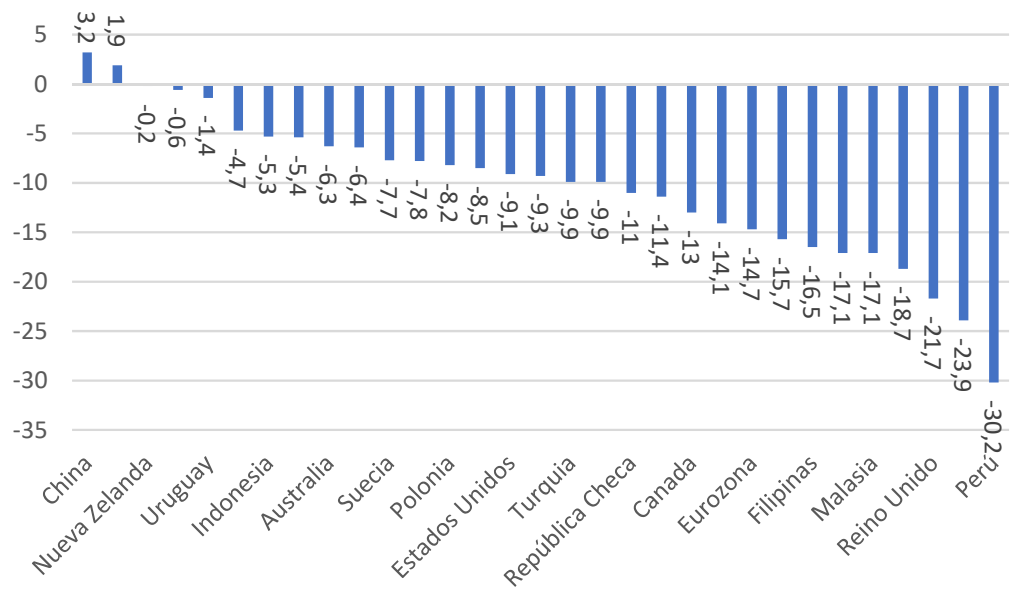

Fuente: Banco Central de Reserva del Perú

La identificación de actividades económicas permitidas y de alto riesgo de contaminación, admiten una mayor efectividad en las políticas económicas aplicadas, así en países como China y Paquistán, las medidas respondían al confinamiento focalizado por actividades económicas que progresivamente se liberan. El número de habitantes también es un factor favorable, porque permite un mejor manejo de las medidas sanitarias como fue el caso de Uruguay que no pasa de los 3,5 millones de habitantes.

En ese contexto, las medidas de concientización adoptados por los gobiernos para mitigar los contagios quedaban en la respuesta de las poblaciones, en la capacidad económica de los estados, y de la disposición de información poblacional para actuar con medidas acertadas.

\subsection{Plan de reactivación económica del Perú y sus consecuencias}

La crisis del Covid19 puso al descubierto los principales problemas estructurales del Perú que fueron ignorados durante veinte años de crecimiento de la economía. Un país resiliente no es solamente aquel que tiene los mejores indicadores macroeconómicos, sino aquel en el que el Estado garantiza a todos sus ciudadanos la cobertura de necesidades básicas como alimentación, salud y educación.

Las medidas para contrarrestar dicho efecto en lo social y minimizar la recesión económica, el gobierno peruano planteó dos fases: 1) fase de contención y 2) fase de reactivación. Para poner en marcha estas dos fases, se previó gasto de manera 
progresiva hasta el $17 \%$ del PBI y se manejaron los siguientes instrumentos de política pública:

- Gasto público, atención de emergencia sanitaria, subvención a las familias, soporte a las empresas, soporte a la cadena de pagos y a la economía.

- Medidas tributarias, postergación de obligaciones tributarias.

- Otras medidas no previstas.

Complementario a estas medidas el plan de reactivación económica consideraba cuatro etapas de intervención ${ }^{13}$ :

a) Etapa de contención (mayo): para desarrollar actividades esenciales alimentarias, industria (seis actividades definidas en el plan), minería (actividades que no incluyan todas las actividades conformantes de los clústeres), construcción (obras públicas y privadas), comercio (actividades de abastecimiento), servicios de turismo (solo restaurantes en la modalidad de entrega a domicilio).

b) Etapa de reactivación incremental (junio): las mismas actividades de la primera etapa, donde se adiciona otro conjunto de actividades para la industria, minería, construcción, comercio, servicios (belleza, peluquerías a domicilio) y turismo (mantiene la única actividad de restaurantes a domicilio).

c) Etapa de reactivación gradual (julio): en la minería sobresalen las actividades del clúster minero incluido minería subterránea y exploración, en construcción mayores proyectos para el sector público, el comercio ya no era minorista sino mayorista, lo cual activó mayores canales de abastecimiento apoyado por el transporte de carga. En la actividad turística se extendería la apertura de restaurantes y promoción al turismo interno.

d) Etapa de recuperación post Covid19 (julio a diciembre): que consiste en el desarrollo de todas las actividades de forma generalizada hasta llegar a la normalidad.

Las medidas de confinamiento paralizaron las actividades económicas. Antes de la pandemia estaba previsto que el Perú crecería 3,8 \% (BCRP, 2020a), la crisis sanitaria provocó una pérdida económica de 15,6 \% en referencia al PBI, el mayor impacto ocurrió en el segundo trimestre del 2020, donde se registró una pérdida de 34,5\% según el Reporte Inflación (BCRP, 2020).

13 En base a datos obtenidos del MEF y PRODUCE se desarrolló una síntesis que exprese el plan de reactivación económica de forma integral. 
El estímulo económico del gobierno fue asegurar el flujo de la cadena de pagos, la estabilidad del sistema financiero con el objetivo de evitar una fuerte recesión que termine con el despido masivo de empleados y quiebre de empresas, otro objetivo planteado fue el distanciamiento social obligatorio con estímulos económicos a las familias.

Las medidas aprobadas eran para asegurar un flujo de 31.457 mil millones de dólares que representa el 14,7 \% del PBI en una primera instancia, hasta alcanzar el $17 \%{ }^{14}$. Este plan de estímulo económico preveía:

a) Medidas tributarias por 4,62 mil millones de dólares para la suspensión de pago de impuestos a las familias, empresas y para facilidades administrativas.

b) Medidas de gasto por 2,92 mil millones de dólares para la atención de emergencia sanitaria, soporte económico a familias y soporte económico a las microempresas y pequeñas empresas.

c) Otras medidas orientadas a exonerar el aporte extraordinario de las empresas Administradoras de Fondos de Pensiones y a un programa de financiamiento denominado Reactiva Perú, que concentraba 17,14 mil millones de dólares para las empresas.

El BCRP en coordinación con el MEF planifican fortalecer el plan de estímulo económico con las siguientes medidas (BCRP; 2020a):

a) Reducción de la tasa de interés de política monetaria, de marzo a abril la tasa de referencia pasó de $2,25 \%$ a $0,25 \%$, fue una política monetaria fuertemente expansiva.

b) Flexibilización de los requerimientos de encaje en soles de 5 \% a 4 \%. Para obligaciones en dólares con plazos menores a dos años para entidades extranjeras se redujo de $50 \%$ a $4 \%$.

c) Provisión de liquidez al sistema financiero. Otorgó operaciones de reporte con fondos de garantía del gobierno para flexibilizar el refinanciamiento de las empresas prestatarias y propuso programas de garantía a la cartera crediticia de las empresas deudoras.

d) Reducción de la volatilidad en las tasas de interés de largo plazo y del tipo de cambio, el BCRP ofertó operaciones de reporte de valores con bonos soberanos y compra directa de moneda extrajera a las Administradoras de Fondos de Pensiones para aliviar el retiro de una parte de los fondos de jubilación de sus ahorristas.

14 Tipo de cambio utilizado para la conversión fue $1 \$$ US. $=$ S/3.5 
d) En junio, el Estado reconoce las limitaciones que tuvo para identificar los hogares vulnerables y personas que componen la actividad informal, toma como medidas correctivas la focalización a través de la oficina de ENAHO, para asignar una subvención económica con el bono denominado Bono Familiar Universal (BCRP, 2020, p.93), la que a la fecha de la culminación de este trabajo aún no se ha distribuido. Queda la duda si se persistirá en la entrega del subsidio en los bancos, puesto que son focos de contagio.

\subsection{Debilidades de la Actividad Económica con las Medidas de Estímulo Económico}

De una revisión al informe del BCRP (2020a, p.53) 29 organizaciones (FMI, WEO, $\mathrm{BM}$, Clasificadoras de riesgo entre otras) en promedio señalaban una recesión de 9,5 \% para el Perú; en el mes de marzo hubo una contracción del PBI del 16,3 \% y en abril del $40,5 \%$.

Las previsiones para el 2021 deberían llevar a que la economía crezca en un $7,0 \%$, siempre que el escenario sea de estabilidad macroeconómica y financiera con reformas orientadas a lograr un entorno adecuado para los negocios que promueva la inversión y el empleo como ha caracterizado al país en los últimos diez años.

El estudio de Reporte Inflación (BCRP, 2020a), señala que el programa de Reactiva Perú ha servido para que la cadena de pagos no se interrumpa, ha proveído de liquidez a las entidades financieras y ha resuelto de manera parcial la penuria de liquidez de las empresas. Las actividades que han sido beneficiadas son: comercio, manufactura y servicios (actividades en transportes y comunicaciones, en el sector inmobiliario).

A junio (BCRP, 2020a) la actividad económica decreció en 12,5 \%, la demanda interna estaba contraída en menos del 9,5\%, las exportaciones habían decrecido en $18,5 \%$, las importaciones en menos $16,5 \%$. A la misma fecha la economía mundial presentaba un decrecimiento de menos de 5,5\%.

Se constató revisando el sitio web oficial del MEF que la reactivación de la economía en el Perú no era dinámica, por ejemplo, el gasto público era lento. A fines de junio las regiones tienen una ejecución presupuestal en promedio del $28 \%$ (MEF, 2020). Los pilares del plan de reactivación en el Perú se sustentaban en la inversión pública y privada; desde el mes de mayo, la ejecución presupuestal del Estado revela la trampa de capacidades donde las autoridades del gobierno central, gobiernos regionales y gobiernos locales se encuentran limitados por sus incapacidades. 
Andrews, Pritchett y Woolcock (2013) sustentan que muchas iniciativas de reforma en los países en desarrollo no logran mejoras sostenidas en rendimiento, porque se encuentran en el mimetismo isomórfico explicado por la incapacidad de los gobernantes, asociado a este problema es la carga prematura. Ello ocurre cuando se implementan políticas que exceden las capacidades de las instituciones, por lo que antes de que puedan adaptarse y soportarlo, terminan colapsando. Esta conceptualización explica por qué el plan de reactivación basado en las iniciativas del Estado está retrasado, igual a la mejora social a través de la generación del empleo por obras públicas.

El retraso de la ejecución presupuestal del gobierno central, gobiernos regionales y municipios en el Perú no solo explica el mimetismo isomórfico por el que atraviesan las autoridades políticas, sino también por el temor de las autoridades a ser denunciadas, dada la intensificación de los permanentes controles de fiscalización de la Contraloría de la República. En plena pandemia se dieron 264 denuncias ante el Ministerio Público en siete regiones del Perú15.

Las encuestas realizadas coinciden con la documentación revisada ${ }^{16}$. La tabla 4 revela que las medidas de política pública no han sido efectivas.

Tabla 4. Percepción sobre políticas públicas.

\begin{tabular}{|c|c|c|c|c|}
\hline Preguntas & Sí & A medias & No & Ignoro \\
\hline \multirow{2}{*}{$\begin{array}{c}\text { La informalidad ha crecido y no contribuirá a la } \\
\text { reactivación }\end{array}$} & 123 & 66 & 26 & 0 \\
\hline & $57,48 \%$ & $30,84 \%$ & $12,15 \%$ & $0,00 \%$ \\
\hline \multirow{2}{*}{ ¿Llega la ayuda económica a las pequeñas empresas? } & 14 & 84 & 94 & 22 \\
\hline & $6,54 \%$ & $39,25 \%$ & $43,93 \%$ & $10,28 \%$ \\
\hline \multirow{2}{*}{$\begin{array}{c}\text { ¿Las microempresas y pequeñas empresas están } \\
\text { preparadas para implementar los protocolos laborales } \\
\text { en la reactivación? }\end{array}$} & 26 & 128 & 49 & 11 \\
\hline & $12,15 \%$ & $59,81 \%$ & $22,90 \%$ & $5,14 \%$ \\
\hline \multirow{2}{*}{$\begin{array}{l}\text { ¿El Estado tiene focalizado a las empresas informales } \\
\text { que requieren de financiamiento? }\end{array}$} & 15 & 60 & 122 & 17 \\
\hline & $7,01 \%$ & $28,04 \%$ & $57,01 \%$ & $7,94 \%$ \\
\hline \multirow{2}{*}{$\begin{array}{l}\text { ¿El Estado ha generado confianza en la población para } \\
\text { el comercio digital? }\end{array}$} & 18 & 78 & 109 & 9 \\
\hline & $8,41 \%$ & $36,45 \%$ & $50,93 \%$ & $4,21 \%$ \\
\hline \multirow{2}{*}{$\begin{array}{c}\text { ¿El Estado está en capacidad de dinamizar la inversión } \\
\text { pública? }\end{array}$} & 37 & 99 & 64 & 14 \\
\hline & $17,29 \%$ & $46,26 \%$ & $29,91 \%$ & $6,54 \%$ \\
\hline
\end{tabular}

Fuente: elaboración propia.

15 La Procuraduría Pública especializada en delitos de corrupción denunció a Gobiernos Regionales, Municipalidades provinciales y distritales, la Policía Nacional del Perú, el MINSA, EsSalud y otros más por delitos de corrupción.

16 Los encuestados son las mismas personas que se describen anteriormente. 
La informalidad es un factor que ha contribuido en el crecimiento de la pandemia, además el confinamiento ha hecho crecer las actividades informales. Así, el 57 \% de los encuestados consideran que no va a contribuir a la reactivación de la economía, además, el 57 \% considera que el Estado no tiene focalizada a las empresas informales. Mientras el $60 \%$ considera que la $\mathrm{MYPE}^{17}$, está preparada a medias para reactivar la economía en condiciones sanitarias que impidan la propagación del virus.

Durante el confinamiento el comercio digital se ha intensificado, sin embargo, el Estado no ha intervenido para generar confianza en la población, por ejemplo, la promoción de ferias digitales, las medidas de control, entre otras. De ahí el hecho que el $51 \%$ los encuestados manifiesten la falta de confianza.

El $46 \%$ de los encuestados perciben que el Estado está preparado medianamente para dinamizar la economía a través de la inversión pública y el 30 \% dice que no está preparado.

\section{CONCLUSIONES}

La pandemia Covid19 ha cambiado la dimensión social, no solo en Perú, sino en todo el mundo, los países han comenzado una transición para salir del distanciamiento social, la continuidad del prolongamiento trae perjuicios económicos que terminan dañando la economía de las familias; no se puede señalar éxitos o fracasos en políticas públicas debido a las variadas características sociales de cada país.

El levantamiento de la cuarentena focalizada sigue siendo un tema políticamente complicado en la vida de los peruanos, la rápida expansión del virus ha puesto en evidencia que las medidas sanitarias no fueron efectivas.

Las medidas económicas en teoría estaban bien planteadas, pero la lentitud del gasto público, como la subvención al sector empresarial no ha llegado con prontitud, lo que pone en evidencia la poca efectividad de la política. El Estado está condenado a no volver al confinamiento y la inmunidad del rebaño será la responsabilidad de cada peruano.

La reflexión del grupo de investigadores plantea como lineamientos de solución lo siguiente:

a) Mejoras en el sistema de salud:

Se debe reevaluar la capacidad del sistema de salud y fijarse metas en cuanto a la implementación en infraestructura, equipos, protocolos de seguridad para el

\footnotetext{
17 Microempresa y pequeña empresa (MYPE)
} 
personal y planificar la incorporación de personal médico que tome en cuenta a aquellos profesionales que están en últimos años de las carreras médicas, de esta forma atender a la población víctima del Covid19. En el estudio no se puso en evidencia la escasez de personal médico que afronta el Perú. Por tanto, las mejoras deben estar proyectadas al menos hasta finales del 2021. El derecho a la salud se debe masificar a toda a la población, incluyendo a extranjeros.

b) Protocolos sanitarios:

Los protocolos sanitarios deben incorporar la instalación de servicios públicos como agua potable que permita el lavado de manos en las zonas pobres, zonas urbanas y rurales vulnerables. La experiencia de países con protocolos simples, donde las empresas puedan condicionar sus instalaciones y horarios para reducir la concentración de personas. El Estado debe contar con medios para concientizar, subvencionar la implementación de protocolos y controlar a las empresas para el cumplimiento de estos.

c) Masificación de pruebas serológicas:

Los científicos peruanos han desarrollado una prueba rápida molecular que puede mejorar el diagnóstico veloz con menor margen de error. El gobierno debe normar la elaboración de estas pruebas en el ámbito nacional y fomentar su producción masiva, de modo que se cuente con métodos de diagnóstico rápido, barato y adecuado.

d) Conectividad:

El Estado debe promover el comercio digital generando confianza en el consumidor, con sistemas de control que certifiquen su protección, también garantizar la gratuidad de la educación y formación profesional a través del internet lo que debe intensificarse. El Estado debe fomentar el trabajo remoto, incentivando tributariamente a las empresas que implementen estos mecanismos, este conjunto de medidas evitará la movilización de las personas disminuyendo su exposición al contagio.

e) Informalidad:

La formalidad de las empresas y del empleo es una necesidad prioritaria para la economía peruana, ya que si los actores del sector informal no perciben los beneficios de la formalidad seguirán actuando como lo hacen desde hace décadas. 
f) Movilización urbana e interprovincial:

Un segmento importante del transporte público a nivel nacional opera informalmente, la flota actual en muchas regiones y ciudades es insuficiente e insegura, en plena pandemia el transporte informal ha imperado con la permisión de las autoridades. Se requiere de nuevos mecanismos de control donde la policía no sea necesariamente quien controle el cumplimiento de las normas de transporte.

Para una mayor efectividad en la ejecución presupuestal por parte del Estado, se debe incorporar a las universidades, empresas y sociedad civil en la formulación de los proyectos de inversión pública, en los concursos públicos de licitación y adjudicación de obras, dado que se vive un estado de emergencia que requiere intervención rápida.

\section{REFERENCIAS}

Andrews, M., Pritchett, L., y Woolcock, M. (2013). Escaping capability traps through problem driven iterative adaptation (PDIA). doi: 10.1016/j.worlddev.2013.05.011

Banco Central de Reserva del Perú BCRP. (2020a). Reporte de Inflación - Junio 2020 - Panorama actual y proyecciones macroeconómicas 2020-2021. https://www.bcrp.gob.pe/docs/Publicaciones/ Reporte-Inflacion/2020/junio/reporte-de-inflacion-junio-2020.pdf

Banco Central de Reserva del Perú. (2020b). Reporte de Inflación Junio 2020: Panorama actual y proyecciones macroeconómicas 2020-2021. [Archivo de Video]. Revisado August 12, 2020. https:// www.youtube.com/watch?v=G30JyFl-79g

Barrios, R. (abril del 2020). Bajo criterios económicos-productivos y de mitigación de riesgo de contagio del COVID-19. Ministerio de la Producción. Recuperado de: http://observatorioviolencia.regionica.gob.pe/images/documentos/20200419\%20PPT\%20Propuesta\%20de\%20 reactivacio\%CC\%81n\%20econo\%CC\%81 mica.pdf

Colegio de Médicos del Perú (5 junio del 2020). Noticias Destacadas se incrementa a 47 el número de médicos fallecidos. https://www.cmp.org.pe/se-incrementa-a-47-el-numerode-medicos-fallecidos/

Defensoría del Pueblo. (20 de Agosto de 2020a). Solo quedan 17 camas UCI con ventilador en Lima Metropolitana y el Callao. Defensoría del Pueblo. https://www.defensoria.gob.pe/defensoria-del-pueblo-solo-quedan-17-camas-uci-con-ventilador-en-lima-metropolitana-y-el-callao/

Díaz, J., Beverinotti, J., Andrian, L., Castellani, F., Abuelafia, E., Manzano, O. y Castilleja, L. (abril del 2020). El impacto del COVID-19 en las economías de la región (región Andina). Recuperado de: http://dx.doi.org/10.18235/0002281

Espinoza Mora, M. del R., Lazo-Páez, G., y Schauer, C. (2017). Vacunación en adultos. Acta Médica Costarricense, 59(2), 50-59. http://www.scielo.sa.cr/scielo.php?script=sci_arttextEpid=S0001$60022017000200050 \xi \operatorname{lng}=$ enEtlng $=$ es. 
Freitas, Carlos Machado de, Silva, Isadora Vida de Mefano e, E Cidade, Natália da Cunha. (2020). Covid-19 as a global disaster: Challenges to risk governance and social vulnerability in Brazil. Ambiente E Sociedade, 23, e0115. Epub July 03, 2020. doi: https://doi.org/10.1590/1809_ -4422 asoc20200115vu202013id

Galán-Rodas, E., Tarazona-Fernández, A., y Palacios-Celi, M. (2020, junio 27). Riesgo y muerte de los médicos a 100 días del estado de emergencia por el COVID-19 en Perú. Acta Médica Peruana, 37(2):119-21. doi: https://doi.org/10.35663/ amp.2020.372.1033

Herrera, D. (2020). ¿Enfrentar el COVID 19 o aprender de su embate? Editorial, 5. doi: https://doi. org/10.23936/pfr.v5i1.149

Herrera Romero, T., y Reys, A. (2020). Empobrecimiento de los hogares y cambios en el abastecimiento de alimentos por la COVID-19 en Lima, Perú. Revistes Científiques de la Universitat de Barcelona, 24(0). doi: https://doi.org/10.1344/ara2020.243.31627.

Instituto Nacional de Estadística e Informática (agosto del 2019). Tasa de empleo informal, según ámbito geográfico, 2008-2018. https://www.inei.gob.pe/estadisticas/indice-tematico/ employed-economically-active-population/

Johns Hopkins University (2020). Número acumulado de casos confirmados, muertes y recuperaciones del coronavirus en Estados Unidos entre el 22 de enero y el 23 de mayo de 2020. https://es.statista.com/estadisticas/1 $107601 /$ covid-19-casos-confirmados-muertes-por-dia-ee-uu/

Ministerio de Economía y Finanzas (MEF). (junio del 2020). Reporte de análisis de ejecución presupuestal. Recuperado de: https://www.mef.gob.pe/contenidos/presu_publ/documentac/ Reporte_Presupuesto_062020.pdf

Ministerio de Salud (MINSA). (2020). Sala Situacional Covid-19 Perú. Boletín diario. Perú. Recuperado en marzo, abril y mayo del 2020. https://covid19.minsa.gob.pe/sala_situacional.asp

Ministero della Salute; Presidenza del Consiglio dei Ministri. (junio de 2020). Número acumulado de casos confirmados, muertes y recuperaciones del coronavirus en Italia entre el 12 de febrero y el 4 de junio de 2020. (S. R. Department, Recopilador) Italia. https://es.statista.com/ estadisticas/1 107849/covid-19-casos-confirmados-muertes-y-recuperados-por-dia-italia/

Moquillaza-Alcántara, V., Romero-Celdán, A., Munares-García, O. y Merellano-Navarro, E. (2020). Variación de los Indicadores Epidemiológicos Del Covid-19 a partir de las políticas de emergencia adoptadas en países sudamericanos. 3-6.doi: https://doi.org/10.1590/ SciELOPreprints. 161

Noticias, R. (Ed.). (06 de mayo de 2020). Cusco: Hospital Regional y de Contingencia no tienen equipos para atender a pacientes con la COVID-19. RPP. Recuperado el 28 de Mayo de 2020. https://rpp.pe/peru/cusco/coronavirus-peru-hospital-regional-y-de-contingencia-no-tienen-equipos-para-atender-a-pacientes-con-la-covid-19-noticia-1263761

Pont Vidal, J. (18 de junio del 2020). Gobernanza de la pandemia Covid-19 y modelos de gestión: ¿Hacia un nuevo tipo de vínculo sociedad-Estado? Escala Nacional de AdminitraÇao Pública. doi: https://doi.org/10.21874/rsp.v71i0.4833 
Pons Rafols, X. (2020). La COVID-19, la salud global y el Derecho internacional: una primera aproximación de carácter institucional. Revista Electrónica de Estudios Internacionales, 2020(39). doi: https://doi.org/10.17103/reei.39.06

Procuraduría Pública Especializada en Delitos de Corrupción (PPEDC). (2020) Boletín Informativo N01 "Corrupción en la Emergencia Sanitaria covid-19"

Semana Económica (12 de Abril del 2020). Retiro de 25\% no afectaría BVL. Selección digital. Semana Económica, p.16.

Statista, RTVE (junio de 2020). Número acumulado de casos confirmados, muertes y recuperaciones del coronavirus en España entre el 15 de febrero y el 4 de junio de 2020. Recuperado el 05 de junio del 2020. http://es.statista.com/estadisticas/1 107506/covid-19-casos-confirmados-muertes-y-recuperados-por-dia-espana/

Vera Calderón, A. F., y Piscoya, A. (2020, Marzo 25). En momentos de pandemia. doi.org/10.1344/ ara2020.243.31627 


\section{ANEXO}

El objetivo de esta encuesta es generar datos originales que fortalezcan la revisión de información secundaria colectada para el logro del supuesto planteado: las medidas implementadas por el gobierno peruano no fueron efectivas para enfrentar la pandemia de la COVID-19

Fue realizado en Google Formulario con un total de 13 preguntas, activa entre las 13:00 horas del sábado 03 y las 13:00 horas del lunes 05 de octubre. El cuestionario se compartió a través de un enlace en grupos de WhatsApp funcionarios del Estado, profesionales, en amas de casa, desempleados por circunstancia de la COVID-19, empresarios de la microempresa y pequeña. También se difundió vía Facebook en páginas de gobiernos regionales, municipalidades. En total, se obtuvieron 214 respuestas.

\begin{tabular}{|c|c|c|c|c|c|c|c|c|c|}
\hline \multicolumn{6}{|c|}{ Opinión sobre las políticas sanitarias } & \multicolumn{4}{|c|}{ RESPUESTAS } \\
\hline & $\begin{array}{l}\text { Funcionarios } \\
\text { del Estado }\end{array}$ & $\begin{array}{l}\text { Profesionales } \\
\text { con trabajor } \\
\text { remoto }\end{array}$ & $\begin{array}{l}\text { Amas de } \\
\text { casa }\end{array}$ & $\begin{array}{l}\text { Desempleados } \\
\text { por } \\
\text { circunsatancias } \\
\text { del COVID-19 }\end{array}$ & $\begin{array}{l}\text { empresarios } \\
\text { micro } \\
\text { empresas y } \\
\text { pequeñas }\end{array}$ & $\mathrm{SI}$ & Amedias & NO & Ignoro \\
\hline $\begin{array}{l}\text { La población está informada sobre higiene } \\
\text { distanciamietno social basado en } \\
1 \text { protocolos biosanitarios }\end{array}$ & & & & & & & & & \\
\hline $\begin{array}{l}\text { Era necesaria la cuarentena, sino habria } \\
2 \text { más muertos }\end{array}$ & & & & & & & & & \\
\hline $\begin{array}{l}\text { No llegó el subisidio económico a las } \\
3 \text { familias que necesitaban }\end{array}$ & & & & & & & & & \\
\hline $\begin{array}{l}\text { Se tiene implementado el sistema y } \\
4 \text { seguimiento de contagiados }\end{array}$ & & & & & & & & & \\
\hline $\begin{array}{l}\text { El Estado ha logrado focalizar los focos de } \\
5 \text { contagio }\end{array}$ & & & & & & & & & \\
\hline $\begin{array}{l}\text { La informalidad al ser alta ignora sobre } \\
6 \text { protocolos sanitarios }\end{array}$ & & & & & & & & & \\
\hline $\begin{array}{l}\text { La informalidad en el transporte urbano e } \\
\text { interprovincial contribuyó al contagio del } \\
7 \text { CovID-19 }\end{array}$ & & & & & & & & & \\
\hline
\end{tabular}

\begin{tabular}{|c|c|c|c|c|c|c|c|c|c|c|}
\hline \multicolumn{7}{|c|}{ Opinión sobre eficiencia en la reactivación económica } & \multicolumn{4}{|c|}{ RESPUESTAS } \\
\hline & & $\begin{array}{l}\text { Funcionarios } \\
\text { del Estado }\end{array}$ & $\begin{array}{l}\text { Profesionales } \\
\text { con trabajor } \\
\text { remoto }\end{array}$ & $\begin{array}{l}\text { Amas de } \\
\text { casa }\end{array}$ & $\begin{array}{l}\text { Desempleados } \\
\text { por } \\
\text { circunsatancias } \\
\text { del COVID-19 }\end{array}$ & $\begin{array}{l}\text { empresarios } \\
\text { micro } \\
\text { empresas y } \\
\text { pequeñas }\end{array}$ & $\mathrm{SI}$ & Amedias & NO & Ignoro \\
\hline & $\begin{array}{l}\text { La informalidad ha crecido y no se sentirá a } \\
\text { reactivación }\end{array}$ & & & & & & & & & \\
\hline & $\begin{array}{l}\text { No llega la ayuda económica a las } \\
\text { pequeñas empresas }\end{array}$ & & & & & & & & & \\
\hline & $\begin{array}{l}\text { Muy pocas micro empresas y pequeñas, } \\
\text { están preparadas para implementar los } \\
\text { protocolos laborales en la reactivación }\end{array}$ & & & & & & & & & \\
\hline & $\begin{array}{l}\text { El Estado tiene focalizado a las empresas } \\
\text { informales que requieren de } \\
\text { financiamiento }\end{array}$ & & & & & & & & & \\
\hline & $\begin{array}{l}\text { El Estado no ha generado confianza en la } \\
\text { población para el comercio digital }\end{array}$ & & & & & & & & & \\
\hline & $\begin{array}{l}\text { El Estado de forma descentralizada no está } \\
\text { en capacidad de dinamizar la inversión } \\
\text { pública }\end{array}$ & & & & & & & & & \\
\hline
\end{tabular}

